\title{
$e$-Commerce Bargain-Hunting with an unBun Model
}

\author{
Raphael Yahalom \\ MIT- Sloan School of Management \\ Cambridge, MA, USA \\ yahalom@mit.edu
}

\begin{abstract}
First-generation comparison-shopping software tools in general have limitations in dealing with bundled products. A new generic model for e-commerce comparison-shopping, based on a logical unBundling of sellers' offerings, is presented. The model captures dominance relationship between offerings and consumer requirements and may serve as a foundation for a variety of shopping decision support software tools. The model provides a basis for defining notions of bargains and designing algorithms for searching for them. Various implications and remaining challenges are outlined.
\end{abstract}

\section{Introduction}

Bargains-hunting pursuits are as old as markets themselves. Consumers obviously aim to get "good value for money". However it seems that in many circumstances consumers derive a special pleasure from buying a good for a price which is significantly lower than the price they perceive is the normal price for such a good.

How will the emerging electronic markets affect such bargain-hunting pursuits?

Consider a few potentially dominant trends:

- Markets are likely to become more efficient thus driving the prices of goods (especially undifferentiated ones) down towards their marginal costs, as well as potentially driving down the price variance of such goods across sellers;

- On the other hand, consumers' search costs are greatly reduced, enabling consumers to gain fast and easy access to many more potential global sellers;

- Sellers have access to sophisticated technology which increasingly enables them to make comparison shopping more difficult by using techniques such as: dynamic pricing and price discrimination, bundling prod-

\author{
Stuart E. Madnick \\ MIT- Sloan School of Management \\ Cambridge, MA, USA \\ smadnick@mit.edu
}

ucts to more complex packages, promoting intangible qualities such as brand and reputation, developing sophisticated customer loyalty programs, and attempting to block automatic shopping comparison agents;

- On the other hand, consumers may have access to increasingly sophisticated shopping decision support software tools;

It is this last point which we believe will prove the most significant one, and is the one on which this paper focuses.

First-generation relatively simple comparison shopping tools have been emerging for the last few years (e.g. BargainFinder, bf.cstar.ac.com, Travelocity, www.travelocity.com, and Junglee www.junglee.com). The unBun model we present in this paper can be considered as a foundation for more sophisticated effective shopping decision support software tools.

Consider for example the travel industry. De-regulation and intense competition on certain popular routes, have accelerated the commoditization of flight seats, and have driven down the prices of flight ticket, as well as the price difference of tickets of competing airlines.

For example, on May 15th 1998 round-trip flight tickets Boston-London for a departure date of June 2nd 1998 were offered on the Web for $\$ 470$ by British Airways (www.british-airways.com), for $\$ 470$ by Virgin Atlantic (www.fly.virgin.com), and for $\$ 480$ by American Airlines (www.aa.com).

On the other hand, these suppliers are also offering bundled packages, which are harder to compare, for which the price variance is significantly larger.

For example, on that same day, the following offerings were available at the above sites:

- A package for 2 adults which includes round-trip Boston-London flight on Virgin Atlantic, 6 nights at the White House Hotel (4 star - AA rating) in London with continental breakfasts, and airport transfers and a guidebook, for departure on June 2nd, was offered on that day by Virgin Atlantic for \$2468 (www.fly.virgin.com). 
- A package for 2 for the same target date, flying on American Airline and 6 nights at the same White House Hotel, with airport transfers but also with full English breakfasts and a pair of theater tickets, though without the guidebook, was offered by American Airlines for only $\$ 2052$ (www.aa.com).

Thus a rational choice of the first package may be justified if the consumer is willing to pay an extra of roughly $\$ 500$ for the "Experience" of flying Virgin Atlantic.

However, on the same day and for the same target dates, flight-only offerings from Virgin Atlantic (www.fly.virgin.com) and an offering for a 6 night stay at the White House hotel offering from BHRC, a hotel booking agency (www.bhrconline.com), enabled a consumer to create that package (including the Virgin Atlantic flight "Experience") for only $\$ 1960$.

Moreover, on the same day and for the same target date, a similar package with a British Airways flight, and a 6 nights stay at the Royal National Hotel was offered by British Airways (www.british-airways.com) for only $\$ 1543$.

What is an effective model within which to compare such offerings?

What types of decision support tools are required to assist consumers in evaluating such offerings?

How can effective searches be conducted matching consumer requirements with offerings' feature representations?

How can related potentially interesting special opportunity bargains be identified and presented to the consumer?

In this paper we outline a foundation framework, unBun, which relies on fine-grained logical unbundling of offerings to their constituent components to support effective offering comparisons.

The contribution of this work is the development of a new generic model for e-commerce offerings' selection and comparison tools, which:

- Is based on domain-specific ontologies for describing and assessing relevant features.

- Relies on state of the art approaches for general context mediation and wrapping to provide normalized offerings views.

- Represents uniformly product attributes as well as seller and buyer attributes.

- Represents level-of-quality dominance relationships between products and features.

- Maps between consumer requirements and lowest priced corresponding offerings.

- Captures categories of consumer-driven potential bargains.
- Enables controlled execution optimizations and complexity reductions.

The rest of this paper is organized as follows. In the next section we discuss previous work in a number of relevant areas. In section 3 the formal foundations of the unBun modeling of offerings are presented. In section 4 we specify the representation of consumer requirements and their relationship to offerings. In section 5 we introduce the notion of bargains and classify them to two categories. In section 6 we demonstrate the potential of the new framework in the context of realistic examples. Section 7 discusses certain optimization techniques. Finally in section 8 we provide some conclusions and outline areas of further work.

\section{Related Work}

A significant body of research has been carried out in a number of areas relevant to our approach.

The effects of reduction of search costs on competition in electronic markets of differentiated good were investigated by [1]. $[15,6]$ present general pricing strategies for goods in electronic marketplaces.

An empirical price comparison analysis between Web retailers of books and CDs and brick-and-mortars ones surprisingly found (among other findings) significant price dispersion across Internet retailers (as much as $47 \%$ difference between Internet retailers for the exact same book or $C D$ ) [5].

[2] investigated the circumstances under which multiple information goods are likely to be bundled as a single offering.

In $[10,11]$ current shopping comparison approaches and tools are examined and criticized, mostly due to their overemphasize on price and under-emphasis on respective features. The use of approaches such as multi-attribute utility theory [13], and distributed constraint satisfaction [18] is advocated.

The challenge of consistent representation and interpretation of multiple offerings from global sources is related to work on semantic mediation in large scale heterogeneous environments (e.g. [16]). Semantic mediation has been addressed by approaches which may generally be classified to tightly-coupled ones, to loosely-coupled ones, and to hybrid ones (e.g. $[8,9,4])$.

Relatively recent efforts has focused on defining description languages and standards for electronic commerce goods, for example CommerceNet's XML exchange (www.xmlx.com) and RDF (www.w3.org). Web-Wrapping approaches such as [3] enable the mapping of unstructured and semi-structured Web data to a structured form.

Approaches for generic representation of different types of goods and services are beginning to emerge: for example, 
information services [17], electronic tickets [7], or salepromotion coupons [14].

\section{A Market-Offerings Model}

Electronic markets contain a population of buyers and a population of sellers offering multiple goods and services.

As buyers (or software agents on their behalf) determine what to buy, from whom, and under which conditions, they view offerings from sellers.

The set of global offerings from multiple sources (sellers) is modeled as a distributed database. Each offering is represented as a record which is normalized according to domainbased conventions. That is, we assume that domain-specific ontologies are used together with context-mediation techniques or with global-schema techniques (cf. [16, 8, 9, 4]), to convert heterogeneous seller representation of goods and features to a normalized view form, while avoiding syntactic and semantic ambiguities and conflicts.

Such normalized offerings are available to consumers directly from the respective suppliers, or via appropriate intermediary shopping services.

A particular offering from a seller to a (possibly specific) population of buyers, at a particular offer-publication point of time at a particular price, may be associated with information attributes about three dimensions:

1. information about the offered products (i.e. what precisely is the buyer promised to get);

2. information about the offering seller (i.e. who is the entity making the promises);

3. information about a potential offered buyer (e.g. is the offering limited to a particular group of buyers);

For example, as part of a special promotion BritishAirways Airlines may offer flights during March 1999 from Boston to London at a special low fare to MIT affiliates.

The normalized representation of each of the three dimensions of any offering is based on domain-specific generic item classes. Each item class is associated with specific named attributes. Each particular item has an assigned value for each of the named attributes of its class.

For example, a class Flight's named-attributes include among others obvious ones such as: From (which may have values representing an airport at a city); To (which may similarly have values representing an airport at a city); Class (which may have values of economy, business, or first); and Departure Date (which may have a value of a date or a range of dates). However, the Flight class also has less obvious named attributes such as, among many others, FrequentFlyer Miles (which may have values representing number of miles a passenger will receive), and Airport-Tax (which may also have values of yes or no representing whether such tax is already included in the offer).

Note that any feature and general information can in any case be represented within unstructured descriptive attributes, containing for example free text, a picture or a Web URL. Such attributes may provide additional information for ad-hoc consumer evaluations ${ }^{1}$.

Any attribute of any offered good or service, tangible (e.g. meal) or not (e.g. reliability), can be captured in the specified normalized form. Some such attribute values may be based on an assessment ranking, which is possibly subjective. Any offering may contain one or multiple products items (For example a travel package offering may include a product item of class Flight and a product item of class Hotel-Room).

For the rest of this paper we focus mostly on offerings representing products and sellers attributes only. That is, for the most part we consider offerings which are available to any potential buyer. Our discussion below may be generalized in an analogous way to capture offerings which are customized for a particular buyer or a limited population of buyers.

We categorize each named-attribute in each item class to three categories, based on the possible values they may be instantiated with:

1. Orderable superiority - a total order is defined which represents an is_superior_than relationship between values. For example the attribute Class of Flight may be ordered as economy, business, and first, as an increasing superiority order. Similarly, the attributename TravelWatch Airline Quality Assessment may be ordered $c, b$ and $a$ representing increasing quality ${ }^{2}$.

2. Refinable specificity - a hierarchy is defined which represent an is_part_of relationship between values. For example the attribute To of a item-class Flight may have a value of a city (e.g. NYC) or a higher specificity value of an airport (e.g JFK airport). The attribute Departure may have a value of such Feb 15th 1999 am or a higher specificity value such as Feb 15th 1999 9:35am. The attribute Hotel-Name of a item-class Tour-Package may have a set value such as $\{$ Sheraton, Marriot, Hilton $\}$ indicating multiple possibilities, or a higher specificity value such as Hilton ${ }^{3}$.

\footnotetext{
${ }^{1}$ Certain features such a refund-ability may involve more complex value structure. The representation and analysis of such more complex features is a focus of our current work which we do not address in this paper.

${ }^{2}$ Such quality-related values may be based on data obtained from different sources: the supplier himself, some objective assessment of a thirdparty, or feedback accumulated from client populations. As described below for any offering attributes, a consumer may determine which of these quality-related attributes are relevant and reliable for her shopping decision process.

${ }^{3}$ The semantics of a low specificity value in an offering falls to two categories: seller-refinable (e.g. a package offering that promises a night at hotel whose general location is London), and buyer-refinable (e.g. an
} 
3. Unstructured - attributes whose values represent additional information for ad-hoc consumer evaluations but which are not interpreted and are not formally incorporated into the offering comparison model. Such attributes may contain free text, images, or Web URLs ${ }^{4}$.

\section{Requirement Constraints}

During a purchase decision process, a consumer normally has certain basic requirements for candidate offerings. Essentially, such requirements can be regarded as these features (of products and/or sellers) which she deems as a necessary foundation.

We represent such a consumer's set of requirements as a Requirement Constraints set (RC). An RC is a set of items with named-attributes values (identical to the structure of an item set in an offering, described above).

In practice, such RC will be generated and instantiated by the consumer support software based on explicit input by the consumer via an appropriate interactive interface, on internal deductions based on the consumer profile or history, or on default values defined for the particular circumstances.

Two general principles underlying our notion of an RC are:

1. The consumer is, in general, indifferent to attributes and items which are not constrained by the RC.

2. Unless over-ridden by the consumer, the constraints in the RC are interpreted as lower bounds. That is, it is normally assumed that if a consumer constrained a hotel to 4 stars she is willing to stay at a 5 star one (if say, everything else of relevance is equal and the price of the latter is lower). Similarly, if say a consumer constrained an offering to include a Flight item (to London) and a Hotel-Room item (3 nights), it is normally assumed that given an offering that contains both of the above items, with an additional Tour item (in London, and in which the consumer does not have to participate) and is priced lower, such an offering may be considered an acceptable candidate by the consumer.

The following definition introduces a satisfy relation between item sets (which are associated with either offerings or RCs). Intuitively, the satisfy relation between items sets captures the notion of at least as good for the consumer.

Informally, an item set of an offering satisfies an item set of an $\mathrm{RC}$ if the first set contains at least all the required

airline offering of Boston-London flights during March: it is up to the buyer to select the actual date within that interval).

${ }^{4}$ In principle as more of an item's feature are structured within our normalized format the more effective the comparison support models and tools. It is our view that an increasingly many (but certainly not all) comparison-relevant features items will eventually become normalizable. items specified in the second, and at least the required superiority or specificity value levels for corresponding attributenames.

Similarly an item set of an RC is said to satisfy an item set of another RC if these conditions hold (and refinability simply being interpreted as is a-subset-of, for analogous reasons as the ones discussed above).

Definition 1: An item set $\mathcal{T}_{2}$ is said to satisfy an item set $\mathcal{T}_{1}$ (denoted $\mathcal{T}_{2} \gg \mathcal{T}_{1}$ ) if for every item $i_{1}$ in $\mathcal{T}_{1}$ there is a unique corresponding item $i_{2}$ of the same class in $\mathcal{T}_{2}$, such that for every value of an attribute in $i_{1}$, there is a corresponding value in $i_{2}$ which is superior (for ordered attributes), refined (for refinable attributes) or equal ${ }^{6}$.

The following corollary establishes the transitivity of the satisfy relation between item sets.

\section{Corollary 1:}

Let $\mathcal{S}_{1}, \mathcal{S}_{2}$, and $\mathcal{S}_{3}$ be sets of items.

$$
\text { If } \mathcal{S}_{2} \gg \mathcal{S}_{1} \text { and } \mathcal{S}_{3} \gg \mathcal{S}_{2} \text { then } \mathcal{S}_{3} \gg \mathcal{S}_{1}
$$

Proof: By contradiction. Assume that $\mathcal{S}_{3}$ does not satisfy $\mathcal{S}_{1}$ while the above two pre-conditions hold. Definition 1 thus implies that there is at least one item $i_{1}^{\prime}$ in $\mathcal{S}_{1}$ for which there is no corresponding unique item, equivalent, superior, or refined in $\mathcal{S}_{3}$. However due to our first assumption there is such a unique item $i_{2}^{\prime}$ in $\mathcal{S}_{2}$, equal, superior, or refined to $i_{1}^{\prime}$. It follows, that there is no corresponding item in $\mathcal{S}_{3}$ which is equivalent, superior, or refined to $i_{2}^{\prime}$ (otherwise that item would have also been equivalent, superior, or refined to $i_{1}^{\prime}$ ) - contradicting our second pre-condition.

We assume a global network environment in which offerings may be posted by any site at any point of time. We model each offering as:

$$
\left[\text { oid }, t_{\text {oid }}, \text { oset }_{\text {oid }}, \text { price }_{o i d}\right]
$$

where

- $\quad$ oid is a unique identifier of an offering.

- $t s_{o i d}$ is an offering-publication timestamp.

- $\quad$ oset $_{\text {oid }}$ is a set of items of the offering.

- $\quad$ price $_{o i d}$ is the non-negative price of the offering.

\footnotetext{
${ }^{5}$ at least the required specificity of a refinable attribute value is defined as being $a$-subset-of of the corresponding (lower refinement) value if the latter is seller refinable, or as intersecting-with the corresponding value if the latter is buyer refinable. That distinction is due to the fact that the satisfy relation reflects the consumer perspective of at-least-as-good relation.

${ }^{6}$ Note that empty or don't care values need to be defined appropriately for refinable and ordered attributes so that their meaning will be consistent with this definition. Also note that this definition implies that there may be items in $\mathcal{T}_{2}$ for which there is no corresponding items in $\mathcal{T}_{1}$.
} 
From a consumer's perspective, under some circumstances multiple offerings may be integrated, and considered for the sake of evaluation and comparison, as a single integrated offering. Such an integrated offering can be regarded as a proposal (jointly by a number of suppliers) to provide a set of items and a particular price. In fact, a single offering may be viewed as a special case of an integrated offering, and we normally use the term offering to refer to both ${ }^{7}$.

We focus on the minimal price required to satisfy a consumer's Requirement Constraints (RC) set. Intuitively, it is the minimal price of an integrated offerings which contains at least all the required items and attributes, and is associated at least with all the required corresponding superiority and refinement levels ${ }^{8}$.

Definition 2: The minimal price of an Requirement Constraints item set $R C$ in an environment, denoted min.price $(R C)$, is

min.price $(R C)=\min \left(\text { price }_{o i d_{j}}\right)_{\left(\forall \text { oid }_{j}\right)\left(\text { oset }_{o i d_{j}} \gg R C\right)}$

\section{Bargains}

We consider a client comparison-shopping session as consisting of two phases:

1. Query-based selection of a small set of candidate offerings out of a very large population of available globally offerings.

2. Browsing-based detailed evaluation of offerings in the candidate set.

Following each of the phases either a shopping decision is made by the client or a new iteration is initiated in which a refined query is generated and the candidate offerings set is augmented.

In phase 1, given a query which represents a client's basic requirements, the basic reference candidate set is the lowest priced offering (or lowest $n$ such offerings) which satisfies her requirements. We denote the set of all offerings (regular

\footnotetext{
${ }^{7}$ We do not elaborate explicitly in this paper on the fact that an integrated offering may be less convenient for a consumer than a single offering because it requires her to deal with multiple sellers. In general, such a feature can itself be represented explicitly within the item set of an offering. Furthermore, we assume that the consumer can specify some limit on the extent to which she is willing to transact with multiple sellers in a given purchase transaction.

${ }^{8}$ In this paper we mostly ignore global consistency issues arising from the asynchronous nature of information transfer (e.g. offerings being posted, modified, or terminated while a minimal price computation algorithm is being performed). In general such aspects are part of the unBun framework and indeed serve as an important basis for optimization techniques.
}

or integrated) in an environment which satisfy a consumer's constraints RC as $S_{R C}$.

However we further assume that a client may be willing to consider a certain amount of additional flexibility in such a preliminary selection, and be presented with some limited additional offerings in the selected candidate set.

We focus here on cases in which such additional offerings are selected if they are related (in a sense defined below) to the client RC and if they can potentially be considered as exceptionally-attractive opportunities.

In general, A potential bargain for a consumer is an offering associated with a price which is significantly lower than the consumer's perceived valuation of the corresponding goods.

Intuitively potential bargain offerings which can be added to the candidate set fall into two categories:

1. Offerings which do not fully satisfy RC but which have particularly attractive prices.

2. Offerings which are priced higher than the lowest one (or lowest $n$ ) satisfying RC, but which have potentially more desirable goods or features - at extra prices which are particularly attractive.

Specifications are required for constraining which potential bargains are appropriate additions to the candidate set.

In order to incorporate notions of bargains in the above unBun model, we introduce the notion of a constraints envelope around a consumer RC. Each envelope is a set of constraints which is either a relaxation of $\mathrm{RC}$, in which case the envelope is referred to as a Downgrade Constraints Envelope $(D C)$, or is a tightening of $\mathrm{RC}$, in which case the the envelope is referred to as a Upgrade Constraints Envelope (UC).

Intuitively a Downgrade Constraints Envelope defines sets of offerings each of which is associated with some inferior value of goods to the consumer (compared to the reference value of these in offerings satisfying RC). Similarly an Upgrade Constraints Envelope defines sets of offering each of which is associated with some superior value of goods to the consumer ${ }^{9}$.

A consumer may be interested in considering as candidate bargains only offerings which satisfy at least a Downgrade Constraints Envelope. A consumer may be interested in paying an extra price (above the Min.Price) for candidate bargains which satisfy (at least) an Upgrade Constraints Envelope.

\footnotetext{
${ }^{9}$ Note that $\mathrm{RC} \gg \mathrm{DC}$ and so $S_{R C} \subseteq S_{D C}$ and similarly UC $\gg$ RC and so $S_{U C} \subseteq S_{R C}$. Note also that allowing a refinable attribute to assume a different value (that its RC value) can be regarded as a Downgrade Envelope: the new constraint can be considered as a set which includes both values, thus a lower specificity value, thus potentially inferior to the consumer (consistently with the definition of satisfy).
} 
An offering can be considered as a potential bargain only if is associated with a price which is lower by at least some bargain threshold, relative to some reference price.

We distinguish between two types of bargains:

- Base-Level-Relative Bargains: the bargain threshold is determined in relation to the (Min.Price of) the base requirement set of the consumer;

- Same-Level-Relative Bargains: the bargain threshold is determined in relation to the price of other market offerings with the same level of goods valuation (from the consumer's perspective) ${ }^{1011}$.

The second category of bargains reflects the circumstances in which consumers' consumption decisions may be influenced by perceived special opportunities (due either to consumer's winner satisfaction or to the fact that the consumer's own valuation of a good may be influenced by her perception of its normal market price).

To demonstrate the difference between the two bargain categories, consider a consumer who wishes to stay a week in a 4-star hotel (RC), but may be willing to consider very attractive bargains, say associated with at least a 50\% discount, within an envelope that includes 3-star hotels (DC) and 5-star ones (UC). The above first bargain category captures for example cases in which a 3-star hotel offering (DC) is cheaper by more than $50 \%$ than the lowest 4 -star offering (RC).

The second bargain category on the other hand captures for example cases in which a 5-star hotel is cheaper by more than $50 \%$ than the next lowest 5-star offering (or, similarly, a 3-star hotel is cheaper by more than $50 \%$ than the the next lowest 3-star offering).

A consumer may in some cases view such offerings as special opportunities which may affect her normal buying decisions.

Finally, we note that in general Same-Level-Relative bargains may similarly be defined in relation to transaction time dimension (all similar offerings available within some time

\footnotetext{
${ }^{10} \mathrm{We}$ omit from this paper some of the technical details however in principle same level of goods valuation offerings are defined as ones in which attributes corresponding envelope constraints (i.e. relaxed or tightened) need to have the same values in the bargain and in its reference set. Other attributes may range across the values defined by the RC. The intuition behind such definition is based on our model in which the set $\left(S_{D C^{-}}\right.$ $S_{R C}$ ) represents offerings which are acceptable to the consumer but of reduced valuation-level in varying degrees, the set $\left(S_{R C}-S_{U C}\right)$ represents offerings which are of equal valuation-level for the consumer, and the set $S_{U C}$ represents offerings which are of increased valuation-level in varying degrees for the consumer.

${ }^{11}$ In evaluating potential Same-Level-Relative bargains we compare their price to the next highest price of an offering in the set of offerings with the same consumer goods valuation level. In general however the bargain threshold can be evaluated with respect to other aggregate values, such as the average price of offerings in that set.
}

interval) or buyer dimension (all similar offerings available to other population of buyers).

\section{Bargain-Hunting Examples}

We demonstrate the potential of the above unBun concepts using an environment consisting of certain travel packages Web offerings.

The presentation focuses on the internal core-model representation of attributes and requirements rather than on actual user interfaces. Shopping support tools designed on top of such a core model would permit for example various consumer requirement values to be deduced from the consumer profile, past behavior, or domain defaults, in addition to these selected explicitly (or over-ridden) by the consumer.

We note again that bargain threshold values, like any other input, can be set by the software tool, or overridden by the consumer for particular envelopes. Note that such value will only affect whether (and which) additional, potentially interesting opportunity offerings will be presented to the consumer for considerations ${ }^{12}$.

The following are representations of offerings which were available (among many others) on the Web, on May 15th 1998, for round-trips from Boston to London for 2 adults, leaving on June 2nd 1998, for 6 nights ${ }^{13}$.

\footnotetext{
${ }^{12}$ In general bargains will be added to the candidate set presented to the consumer only if they are not strictly dominated by some other offering already in that set (e.g. another bargain which offers at least as much at an even lower price).

${ }^{13}$ For the sake of brevity we omitted any explicit reference to certain attributes such as timing-related ones.
} 
Flights+ Hotel Offerings

\begin{tabular}{|c|c|c|c|c|c|}
\hline & $\frac{\text { Offering } 1}{\text { www.fly.virgin.com }}$ & $\frac{\text { Offering } \mathbf{2}}{\text { www.american.com }}$ & $\frac{\text { Offering } \mathbf{3}}{w w w . b r i t i s h \text {-airways.com }}$ & $\underset{w w w . b r i t i s h \text {-airways.com }}{\text { Offering } \mathbf{4}}$ & $\frac{\text { Offering } \mathbf{5}}{\text { www.british-airways.com }}$ \\
\hline $\begin{array}{l}\text { Airline: } \\
\text { Class : } \\
\text { \#-of-flights : }\end{array}$ & $\begin{array}{c}\text { Virgin } \\
\text { economy } \\
2 \text { round-trips (Bos-Lon) }\end{array}$ & $\begin{array}{c}\text { American } \\
\text { economy } \\
2 \text { round-trips (Bos-Lon) }\end{array}$ & $\begin{array}{c}\text { British-Airways } \\
\text { economy } \\
2 \text { round-trips (Bos-Lon) }\end{array}$ & $\begin{array}{c}\text { British-Airways } \\
\text { economy } \\
2 \text { round-trips (Bos-Lon) }\end{array}$ & $\begin{array}{c}\text { British-Airways } \\
\text { economy } \\
2 \text { round-trips (Bos-Lon) }\end{array}$ \\
\hline $\begin{array}{l}\text { Hotel: } \\
\text { AA-Rating: } \\
\text { Location: } \\
\text { Breakfast: } \\
\text { \#-of-nights: }\end{array}$ & $\begin{array}{l}\text { White House } \\
4 \text { star } \\
\text { central London } \\
\text { continental } \\
6 \text { (double room) }\end{array}$ & $\begin{array}{l}\text { White House } \\
4 \text { star } \\
\text { central London } \\
\text { English } \\
6 \text { (double room) }\end{array}$ & $\begin{array}{c}\text { Russel } \\
4 \text { star } \\
\text { central London } \\
\text { continental } \\
6 \text { (double room) }\end{array}$ & $\begin{array}{c}\text { St Giles } \\
3 \text { star } \\
\text { central London } \\
\text { continental } \\
6 \text { (double room) }\end{array}$ & $\begin{array}{l}\text { Royal National } \\
2 \text { star } \\
\text { central London } \\
\text { continental } \\
6 \text { (double room) }\end{array}$ \\
\hline $\begin{array}{l}\text { Transfers: } \\
\text { \#-of-tickets: }\end{array}$ & $\begin{array}{l}\text { standard } \\
2 \text { trips }\end{array}$ & - & - & - & - \\
\hline Guide book : & & - & - & - & - \\
\hline $\begin{array}{l}\text { Theater Tickets: } \\
\text { \#-of-tickets: }\end{array}$ & - & $\begin{array}{c}\text { standard } \\
2\end{array}$ & - & - & - \\
\hline Total Price: & $\$ 2468$ & $\$ 1962$ & $\$ 2142$ & $\$ 1762$ & $\$ 1543$ \\
\hline
\end{tabular}

Hotel Offerings

\begin{tabular}{|c|c|c|c|c|}
\hline & $\frac{\text { Offering } \mathbf{6}}{\text { www.bhrconline.com }}$ & $\frac{\text { Offering } 7}{\text { www.bhrconline.com }}$ & $\frac{\text { Offering } \mathbf{8}}{\text { www.bhrconline.com }}$ & $\frac{\text { Offering } 9}{w w w . \text { bhrconline.com }}$ \\
\hline $\begin{array}{l}\text { Hotel: } \\
\text { AA-Rating: } \\
\text { Location: } \\
\text { Breakfast: } \\
\text { \#-of-nights: }\end{array}$ & $\begin{array}{c}\text { White House } \\
4 \text { star } \\
\text { central London } \\
\text { continental } \\
6 \text { (double room) }\end{array}$ & $\begin{array}{c}\text { Russel } \\
4 \text { star } \\
\text { central London } \\
\text { continental } \\
6 \text { (double room) }\end{array}$ & $\begin{array}{c}\text { James } \\
4 \text { star } \\
\text { central London } \\
\text { continental } \\
6 \text { (double room) }\end{array}$ & $\begin{array}{c}\text { Savoy } \\
5 \text { star } \\
\text { central London } \\
\text { continental } \\
6 \text { (double room) }\end{array}$ \\
\hline Total Price: & $\$ 1020$ & $\$ 840$ & $\$ 1040$ & $\$ 1400$ \\
\hline
\end{tabular}

Flights Offerings

\begin{tabular}{|c|c|c|c|}
\hline & $\frac{\text { Offering } 10}{\text { www.fly.virgin.com }}$ & $\begin{array}{c}\frac{\text { Offering } \mathbf{1 1}}{\text { www.american.com }} \\
\end{array}$ & $\frac{\text { Offering } \mathbf{1 2}}{\text { www.british-airways.com }}$ \\
\hline $\begin{array}{l}\text { Airline: } \\
\text { Class : } \\
\text { \#-of-flights : }\end{array}$ & $\begin{array}{c}\text { Virgin } \\
\text { economy } \\
2 \text { round-trips (Bos-Lon) }\end{array}$ & $\begin{array}{c}\text { American } \\
\text { economy } \\
2 \text { round-trips (Bos-Lon) }\end{array}$ & $\begin{array}{c}\text { British-Airways } \\
\text { economy } \\
2 \text { round-trips (Bos-Lon) }\end{array}$ \\
\hline Total Price: & $\$ 940$ & $\$ 960$ & $\$ 940$ \\
\hline
\end{tabular}

Theatre Tickets Offering and Airport-Transfer Offering

\begin{tabular}{|l|c|c|} 
& $\frac{\text { Offering 13 }}{w w \text { w.uk-online.com }}$ & $\frac{\text { Offering 14 }}{w w w . u k \text {-online.com }}$ \\
$\begin{array}{l}\text { Transfers: } \\
\text { \#-of-tickets: }\end{array}$ & standard & - \\
$\begin{array}{l}\text { Theater Tickets: } \\
\text { \#-of-tickets: }\end{array}$ & - & - \\
Total Price: & - & standard \\
\hline
\end{tabular}


Assume the following constitutes a consumer's Requirement Constraints set RC ( * represents don't care) :

\begin{tabular}{|ll|}
\hline Airline: & $*$ \\
Class : & economy \\
\#-of-flights : & 2 round-trips (Bos-Lon) \\
& \\
Hotel: & $*$ \\
AA-Rating: & 2 star \\
Location: & Greater London \\
Breakfast: & $*$ \\
\#-of-nights: & 6 (double room) \\
\hline
\end{tabular}

The Min.Price of the set offerings which satisfy this Constraint set is $\$ 1543$ (corresponding to offering 5).

Assume now the following consumer's RC :

\begin{tabular}{|ll|}
\hline Airline: & Virgin \\
Class : & economy \\
\#-of-flights : & 2 round-trips (Bos-Lon) \\
& \\
Hotel: & White House or Grosvenor \\
\#-of-nights: & 6 (double room) \\
Airport transfers: & 2 trips \\
London Guide book : & 1 \\
\hline
\end{tabular}

Assume that a bargain threshold is specified as $15 \%$. A Downgrade Envelope Constraints (DC) is specified as the following possible relaxations to the RC:

\section{\#-of-nights: $\quad 6 \rightarrow \mathbf{5}$ \\ London Guide book : $\quad 1 \rightarrow$ exclude}

The Min.Price satisfying RC is $\$ 2468$ (corresponding to offering 1). However in addition to that offering, the consumer will also be presented with an additional bargain offering for consideration: the integrated offering $\{10,6,13\}$. That offering's price is $\$ 2060$ and it is a Base-Level-Relative Bargain: It satisfies DC (essentially identical product items without the London guidebook) and its price is discounted by more than $15 \%$ compared to the Min.Price of RC. Note that this breakdown implies that in offering 1 the consumer is essentially being charged $\$ 408$ for a single London Guide Book.

Assume the following consumer's RC :

\begin{tabular}{ll|}
\hline Hotel: & $*$ \\
AA-Rating: & 5 star \\
Location: & Greater London \\
Breakfast: & continental \\
\#-of-nights: & 6 (double room) \\
\hline
\end{tabular}

and the following Downgrade envelope (DC) :

\section{AA-Rating: 5 star $\rightarrow \mathbf{4}$}

Offering 9 whose price $(\$ 1400)$ corresponds to the Min.Price of offerings satisfying RC will be presented to the user.

However offering 7 will be presented as well, as a SameLevel-Relative Bargain. Its price of $\$ 840$ is lower by more than 15\% than the price of the next higher offerings (\$1020) of the set of downgraded offerings with the same level of goods quality (which contains offerings 6 and 8 ).

Offering 8 constitutes a Base-Level-Relative Bargain as well.

Assume the following consumer's RC :

\begin{tabular}{|ll|}
\hline Airline: & $*$ \\
Class : & economy \\
\#-of-flights : & 2 round-trips (Bos-Lon) \\
& \\
Hotel: & $*$ \\
AA-Rating: & 3 star \\
\#-of-nights: & 6 (double room) \\
\hline
\end{tabular}

and the following Upgrade Constraints envelope $(U C)$ :

AA-Rating: $\quad 3$ star $\rightarrow \mathbf{4}$

Offering 4 whose price (\$1762) is the Min.Price of the offerings set satisfying $\mathrm{RC}$ will be presented.

The integrated offerings $\{10,7\}$ and $\{12,7\}$ with a price $(\$ 1780)$ will be presented as well as a Same-LevelRelative Bargain. Its incremental price (\$18) represents an over $90 \%$ discount with respect to the next higher incremental price between a similar 3 star hotel room to 4-star hotel room (which is $\$ 198$ ).

Finally assume the following consumer's RC :

\begin{tabular}{|ll|}
\hline Airline: & $*$ \\
Class : & economy \\
\#-of-flights : & 2 round-trips (Bos-Lon) \\
& \\
Hotel: & White House \\
\#-of-nights: & 6 (double room) \\
\hline
\end{tabular}

and the following Upgrade envelope (UC) : 


\section{Theater Tickets (2) include}

The integrated offerings $\{10,6\}$ and $\{12,6\}$ with a price ( $\$ 1960)$ will be presented as the lowest priced offering to satisfy RC.

Offering 2 will be presented as well as a Same-LevelRelative Bargain. Its incremental price of \$2 represents over a $95 \%$ discount with respect to the next lowest incremental price of a pair of theater tickets (offering 14).

\section{Execution Optimizations}

Optimization techniques fall into two complementary categories:

- Techniques which may eliminate in a controlled manner certain sets of offerings (or offering combinations) from consideration relying instead on appropriate sampling or approximations and providing results which are (very likely) close to optimal.

- Techniques which rely on identifying and eliminating computation steps which can be deduced as redundant.

The first category of techniques enables fine-tuning of extra computation costs in a way that reflects the expected potential gain (from increasingly better offerings). The design and analysis of such techniques involves experimentation in the context of particular application domains.

The second category of techniques relies on established formal properties to reduce, where possible, redundant computation steps.

Consider for example a software shopping agent of a consumer that has direct access to certain Minimal Price values (e.g. as a result of previous pre-computed query, or as a result of intentional caching of commonly requested items). In particular let us assume that the agent has access to the fact that the minimal price for round-trip, economy, NY-Paris flight in March is $\$ 550$. Furthermore, assume that the agent also has access to the fact that the minimal price for a package for March which includes round-trip, economy, NY-Paris flight as well as a 2 night stay at a 5-star hotel is $\$ 1050$.

Now assume that the consumer herself is interested in a trip to Paris for 2 nights at 4 star hotel. She specified that she is willing to settle for only a 3 star hotel if there is a particular good bargain (say if she is required to pay $50 \%$ or less for the 3-star hotel package relative to the lowest 4-star offering).

A naive execution of the above requirement would compute the minimal price of the base (4 star) requirements, followed by an evaluation of all appropriate 3 -star offerings (to determine if any is cheaper by at least $50 \%$ than the minimal one of the basic requirement).
However it can immediately be deduced that no such bargain can exist and so that the computation may stop right after completing the calculation of the minimal price for the 4-star case. This is due to the fact that there exist 2 minimal prices for constraint sets, one of which represents looser constraints (flight only) than the ones corresponding to our target bargain (flight and 3-star hotel), and the other which represents tighter constraints (flight and 5-star hotel) than the reference set of the bargain (flight and 4-star hotel) and the ratio between the min.prices corresponding to these extreme constraint sets is higher than 50\%.

The following Lemma establishes this property in general, and enables to deduce in certain cases that certain bargains cannot exist.

\section{Lemma 1:}

Let $\mathcal{S}_{1}, \mathcal{R}_{1}, \mathcal{R}_{2}$ be constraint item sets and oid ${ }_{k}$ be an offering,

If all the following three conditions hold

1. $\frac{\text { min.price }\left(\mathcal{S}_{1}\right)}{\text { min.price }\left(\mathcal{R}_{1}\right)} \geq \frac{100-d}{100}$;

2. oset $_{\text {oid }_{k}} \gg \mathcal{S}_{1}$;

3. $\mathcal{R}_{1} \gg \mathcal{R}_{2}$

Then $\frac{\text { price }_{o i d_{k}}}{\text { min.price }\left(\mathcal{R}_{2}\right)} \geq \frac{100-d}{100}$

Proof: By contradiction.

(1): Assume the three conditions hold and $\frac{\text { price }_{\text {oid }}}{\operatorname{min.price}\left(\mathcal{R}_{2}\right)}<\frac{100-d}{100}$

(2): According to condition 3: oset $_{\text {oid }} \gg \mathcal{S}_{1}$

(3): Thus from definition of Min.Price: price $_{\text {oid }_{k}} \geq \min$. price $\left(\mathcal{S}_{1}\right)$

(4): According to condition 1: $\frac{\text { min.price }\left(\mathcal{S}_{1}\right)}{\text { min.price }\left(\mathcal{R}_{1}\right)} \geq \frac{100-d}{100}$

(5): We deduce from (3) and (4): $\frac{\text { price }_{\text {oid }}}{\text { min.price }\left(\mathcal{R}_{1}\right)} \geq \frac{100-d}{100}$

(6): From (5) and (1): min.price $\left(\mathcal{R}_{2}\right)>$ min.price $\left(\mathcal{R}_{1}\right)$

(7): According to condition 2: $\mathcal{R}_{1} \gg \mathcal{R}_{2}$

(8): Let oid ${ }_{m}$ be the offering of min.price $\left(\mathcal{R}_{1}\right)$

(9): By definition of min.price: oset $_{\text {oid }_{m}} \gg \mathcal{R}_{1}$

(10): But from (7) and Corollary 1 we deduce: oset $_{\text {oid }_{m}} \gg \mathcal{R}_{2}$

(11): Consequently by definition of min.price: min.price $\left(\mathcal{R}_{2}\right) \leq$ price $_{\text {oid }_{m}}$

(12): However from (8) and (11) we deduce: min.price $\left(\mathcal{R}_{2}\right) \leq$ min.price $\left(\mathcal{R}_{1}\right)$, a contradiction with (6).

This and other such properties may be used to significantly reduce in some cases the computation by early elimination of redundant steps. 


\section{Conclusions and Further Work}

In general, consumers often do not make offering selection decisions based purely on the price difference. However, the nature of electronic markets and the availability of tools based on frameworks such as unBun will increase the degree of rational quantitative selection criteria, for two main reasons:

1. It will increasingly enable the decomposition of virtually all aspects of an offering into explicit, quantifiable, dimensions (e.g. reputation of the supplier, reliability of product, etc.).

2. Applications can perform increasingly complex quantitative analysis, based on paradigm such as the ones presented here, on behalf of consumers, while retaining their conceptual and user-friendly appeal.

The contribution of the work presented in this paper is a new generic model, unBun, for effective consumer shopping-support tools which assist in searching and comparing relevant offerings.

Normally a consumer inputs some requirements and is presented with the least expensive offerings which satisfy it. However, our approach enables to also find and present particular attractive opportunities which are close to the user basic requirements, in the sense that they are within some envelope defined around these requirements.

The satisfies relation in unBun between offerings and requirements and the dominance implied, enable to define notions of bargains in a meaningful and consistent manner. In consumer support software tools which are based on the unBun model, many of the consumer requirements can be derived automatically, or be over-ridden by explicit input from the user. Similarly, the acceptable bargain envelopes around the requirements can often be based on default notions of value acceptable proximity, which can also be over-ridden as required.

Optimizations techniques enable to fine-tune the performance and complexity to reflect expected potential gains.

Our current work on the unBun approach is focused on a number of main areas:

- Incorporation within unBun notions of more complex item features such as options, after-the-fact changes, cancellation, insurance, discount coupons, and others.

- Design and implementation of a Web-based prototype system.

- Empirical analysis of potential bargain offerings in selected industries.

- Experimentation with real consumers in realistic offering comparison settings.

\section{References}

[1] Y. Bakos "Reducing Buyer Search Costs: Implications for Electronic Marketplaces" Management Science, Vol. 43, No. 12, Dec. 97.

[2] Y. Bakos and E. Brynjolfsson "Aggregation and Disaggregation of Information Goods: Implications for Bundling, Site Licensing, and Micropayment Systems", Conference on Internet Publishing and Beyond: The Economics of Digital Information and Intellectual Property, Harvard University, 1997.

[3] S. Bressan and P. Bonnet "Extraction and Integration of Data from Semi-structured Documents into Business Applications", Conference on the Industrial Applications of Prolog , 1997.

[4] S. Bressan, K. Fynn, C. Goh, S. Madnick, T. Pena, and M. Siegal "Overview of a Prolog Implementation of the Context Interchange Mediator", Proceedings of the International Conference on Practical Applications of Prolog, 1997.

[5] E. Brynjolfsson amd M. D. Smith "Frictionless Commerce? A Comparison of Internet and Conventional Retailers" MIT-Sloan School of Management, Working Paper, January 1999.

[6] A. Cortese and M. Stepanek "Good-Bye to Fixed Pricing?" Business Week, May 4th, 1998, pp. 71-84.

[7] K. Fujimura and Y. Nakajima, "General-purpose Digital Ticket Framework", in Proceedings of the 3rd Usenix Workshop on Electronic Commerce, Boston, Sept 1998.

[8] C.H.Goh "Representing and Reasoning about Semantic Conflicts in Heterogeneous Information Systems" Ph.D Thesis, MIT-Sloan School of Management, 1996.

[9] C.H.Goh, S. Bressan, S. Madnick, M. Siegel, "Context Interchange: New Features and Formalisms for the Intelligent Integration of Information", ACM Transactions on Information Systems, Vol. 17, Num. 3, (to appear).

[10] R.H. Guttman and P. Maes "Agent-mediated Interactive Negotiation for Retail Electronic Commerce", Proceedings of the Workshop on Agent Mediated Electronic Trading (AMET'98), Minneapolis, Minnesota, May 1998.

[11] R.H. Guttman and P. Maes "Cooperative vs. Competitive Multi-Agent Negotiations in Retail Electronic Commerce", Proceedings of the Second International Workshop on Cooperative Information Agents (CIA’98), Paris, France, July 3-8, 1998. 
[12] G. Haubl and V. Trifts "Consumer Decision Making in Online Shopping Environments: The Effects of Interactive Decision Aids" University of Alberta, Faculty of Business, Working Paper, March 1999.

[13] R. Keeney and H. Raiffa "Decisions with Multiple Objectives: Preferences and Value Tradeoffs", John Wiley and Sons, 1976.

[14] M. Kumar, A. Rangachari, A. Jhingran, and R. Mohan, "Sales Promotions on the Internet", in Proceedings of the 3rd Usenix Workshop on Electronic Commerce, Boston, Sept 1998.

[15] H. G. Lee " Do Electronic Marketplaces Lower the Price of Goods?", Communications of the ACM, Vol. 41, No. 1, January 1998.

[16] S. Madnick, "Are We Moving Towards an Information Superhighway or a Tower of Babel? The Challenge of Large-Scale Semantic Heterogeneity"Proceedings of IEEE International Conference on Data Engineering, 1996, pp. 2-8.

[17] T. Mullen and M. Wellman, "The Auction Manager: Market Middleware for Large-Scale Electronic Commerce", in Proceedings of the 3rd Usenix Workshop on Electronic Commerce, Boston, Sept 1998.

[18] E. Tsang "Foundations of Constraints Satisfaction" Academic Press , 1993. 